\title{
Optimal timing for heart transplantation in patients bridged with left ventricular assist devices: Is timing of the essence?
}

\author{
Chase R. Brown, MD, ${ }^{\mathrm{a}, \mathrm{b}}$ Fabliha Khurshan, BA, ${ }^{\mathrm{a}}$ Zehang Chen, BA, BSN, ${ }^{\mathrm{a}}$ Peter W. Groeneveld, MD, ${ }^{\mathrm{b}, \mathrm{c}}$ \\ Fenton McCarthy, MD, MS, ${ }^{a}$ Michael Acker, MD, ${ }^{a}$ J. Eduardo Rame, MD, ${ }^{d}$ and Nimesh Desai, MD, PhD ${ }^{\mathrm{a}, \mathrm{b}}$
}

\section{ABSTRACT}

Objectives: Due to the scarcity of donor hearts to meet recipient demands, more than $40 \%$ of heart transplants are performed in patients bridged to transplant (BTT) with a left ventricular assist device (LVAD). The objective of this study was to determine the effect of BTT duration with an LVAD on posttransplant outcomes.

Methods: From 2009 to 2014, we identified 2639 fee-for-service Medicare patients who underwent a primary heart transplants with $1186(45 \%)$ patients BTT with an LVAD. The LVAD patients were stratified as BTT $\leq 31$ days $(\mathrm{n}=28[2.4 \%])$, BTT 31-365 days $(\mathrm{n}=748[63.1 \%])$, and BTT $>365$ days $(\mathrm{n}=409[34.5 \%])$. Patients went directly to heart transplantation and were not bridged in 1453 cases (55\%). LVAD duration was analyzed dichotomously and as a continuous variable with adjusted overall survival as the primary end point.

Results: All-cause mortality was significantly worse in patients who were BTT $<31$ days. Survival at 30 days was $81.5 \%$ for BTT $<31$ days, 94\% for BTT 31 to 365 days, $95 \%$ for BTT $>365$ days, and $94 \%$ for no BTT. At 1 year, survival was $74 \%$ for BTT $<31$ days, $85 \%$ for BTT 31 to 365 days, $88 \%$ for BTT $>365$ days, and $89 \%$ for no BTT $(P=.018)$. When LVAD duration was analyzed as a continuous variable, patients BTT with an LVAD $<34$ days had significantly increased mortality.

Conclusions: Patients who underwent heart transplantation within the first month of BTT with an LVAD had significantly increased mortality. However, there was no survival difference among patients who were BTT with an LVAD longer than 31 days. (J Thorac Cardiovasc Surg 2019;157:2315-24)

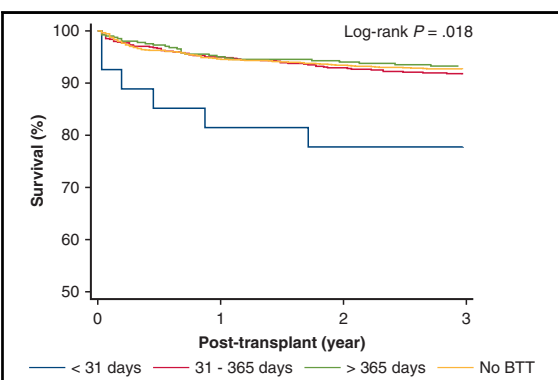

Risk of death after heart transplant based on bridge to transplant duration with an LVAD.

\section{Central Message}

The risk of mortality after heart transplantation was greatest when bridge to transplant duration with a left ventricular assist device was $<1$ month before transplant.

\section{Perspective}

Due to the scarcity of donor hearts, it is critical to determine how BTT duration with an LVAD influences outcomes after transplantation. We found that patients BTT $<1$ month have decreased survival, but patients BTT longer than 1 year have increased complications after transplant. This may suggest that earlier transplantation within the first year can improve outcomes.

See Commentaries on page 2325 and 2327.

\footnotetext{
From the Divisions of ${ }^{\mathrm{a}}$ Cardiovascular Surgery and ${ }^{\mathrm{d}}$ Cardiovascular Medicine, Hospital of the University of Pennsylvania, Philadelphia, Pa; ${ }^{b}$ Leonard Davis Institute of Health Economics, University of Pennsylvania, Philadelphia, Pa; and ${ }^{\mathrm{c}}$ Michael J. Crescenz VA Medical Center, Philadelphia, Pa.

Supported by National Research Service Award (NSRA) T32 training grant No. T32HL007843.

Read at the 98th Annual Meeting of The American Association for Thoracic Surgery, San Diego, California, April 28-May 1, 2018.

Received for publication May 5, 2018; revisions received Nov 29, 2018; accepted for publication Dec 25, 2018; available ahead of print April 5, 2019.

Address for reprints: Nimesh Desai, MD, PhD, Division of Cardiac Surgery, Hospital of the University of Pennsylvania, 3400 Spruce St, Silverstein 6, Philadelphia, PA 19104 (E-mail: Nimesh.Desai@uphs.upenn.edu).

0022-5223/\$36.00

Copyright (c) 2019 Published by Elsevier Inc. on behalf of The American Association for Thoracic Surgery

https://doi.org/10.1016/j.jtcvs.2018.12.118
}

The incidence of heart failure is increasing in the United States. ${ }^{1}$ Medical therapies for heart failure are limited, and many patients require heart transplant (HTx). Due to

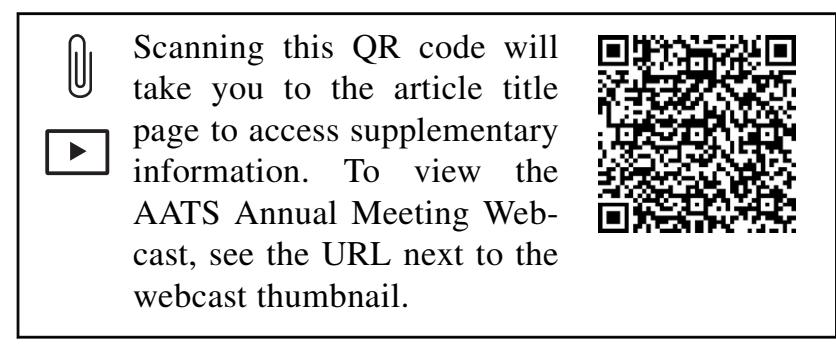




\section{Abbreviations and Acronyms \\ BTT = bridged to transplant \\ HTx $=$ heart transplant \\ ICD-9 $=$ International Classification of Diseases ninth revision \\ LVAD $=$ left ventricular assist device}

the lack of donor hearts to meet the demands of patients with end-stage heart failure, left ventricular assist devices (LVADs) have been increasingly utilized in this population to prolong survival and bridge patients successfully to transplantation. ${ }^{2-6}$ In the United States, approximately $40 \%$ of all $\mathrm{Htx}$ procedures are completed in patients bridged to transplant (BTT) with an LVAD. Among these patients who are selected for transplantation, recent evidence with continuous flow devices suggests no differences in mortality compared with patients that go directly to HTx. ${ }^{7-10}$ However, very few studies have investigated the influence on the duration of BTT with an LVAD on posttransplant outcomes. The 2 most recent studies demonstrated no survival difference based on the duration of BTT with a LVAD, yet these reports were either limited to short follow-up times or conducted as a small, singlecenter experience. ${ }^{11,12}$ Older studies that investigated this topic were completed in patients with pulsatile devices and do not reflect current practice patterns. ${ }^{13,14}$

Due to the scarcity of donor hearts, it is critical to determine how BTT duration with an LVAD influences outcomes after transplantation. This could lead to new policies to help risk-stratify patients on the waiting list and to improve patient selection, with the goal to better allocate limited resources. We performed a cross-sectional analysis among Medicare patients who underwent HTx from 2009 to 2014. Patients were stratified based on BTT duration with an LVAD and compared with patients not bridged with an LVAD to evaluate posttransplant survival and complications.

\section{METHODS \\ Study Design}

We performed a retrospective cross-sectional analysis of fee-for-service Medicare patients from 2009 to 2014 in patients who underwent HTx. Patients were stratified based on the presence and duration of an LVAD before HTx: BTT $<31$ days, BTT 31 to 365 days, BTT $>365$ days, and no BTT. Patient groups were compared to determine differences in all-cause mortality, cumulative incidence for postoperative complications, and hospital readmissions.

\section{Study Population and Data}

All patients were identified from Medicare Carrier Files using Current Procedural Terminology codes to identify HTx patients (Table E1). Between January 1, 2009, and December 31, 2014, we identified 3187 patients who underwent HTx. Primary HTx occurred in 2639 patients during that time period. Patients were then stratified based on BTT status with an LVAD. We identified 1713 (54\%) patients who were BTT with an LVAD that was explanted on the day of the HTx procedure. We excluded 528 patients who had no date associated with their LVAD implantation because the implant occurred before entering Medicare. We also excluded 21 patients that had missing or incomplete data. Furthermore, patients with right ventricular assist devices, biventricular assist devices, total artificial hearts, and extracorporeal or percutaneous LVADs were not included in the study Additionally, patients undergoing abdominal transplant concomitantly with the HTx were not included. BTT patients were stratified into the early or late group based on BTT timing with 28 patients $(2.4 \%)$ BTT $\leq 31$ days, 748 patients (63.1\%) BTT 31 to 365 days, and 409 patients (34.5\%) BTT $>365$ days. Patients went directly to HTx and were not bridged in 1453 patients $(55 \%)$. These time cutoffs were selected based on study design and data presentation of previous manuscripts. ${ }^{11,12,14}$ In addition to dichotomizing duration on LVAD support before transplantation, BTT duration was also analyzed as a continuous variable. Figure 1 presents the flow chart for patient inclusion and exclusion criteria.

All patients were linked to Medicare Denominator and Beneficiary Summary Files to determine patient demographic characteristics and death status. The Medicare Provider Analysis and Review Files and Carrier Files were used to determine details about the index hospitalization such as length of stay, discharge location after HTx, and posttransplant in-patient hospital readmissions. Patient comorbidities were determined from the previous hospitalizations, outpatient files, or present on admission at the primary hospitalization for heart transplantation within the MedPAR and Carrier Files using International Classification of Diseases ninth revision (ICD-9) codes and categorized with the Elixhauser comorbidity index ${ }^{15,16}$ (Table 1). Tables E2 and E3 present the ICD-9 and Current Procedural Terminology codes used to determine patient comorbidities and preoperative characteristics.

For patients who were BTT, we determined whether they had any LVADrelated complications within 30 days before transplant (Table 1). These data were utilized in the multivariable survival model to analyze whether LVAD complications influenced the need for HTx and postoperative outcomes. LVAD complications were grouped as mechanical complications, pump thrombosis, local/systemic infection, gastrointestinal bleeding, cerebral bleeding, and other major bleeding events. ${ }^{17}$ Right heart failure could not be investigated because there is no specific ICD-9 code for this diagnosis.

\section{Outcomes}

The primary end point was adjusted all-cause mortality among the BTT $<31$ days, BTT 31 to 365 days, BTT $>365$ days, and no BTT. Secondary end points included posttransplant complications at 30 days and 1 year for stroke, pneumonia, respiratory failure, tracheostomy, sepsis, acute kidney injury, hemodialysis, end-stage renal disease, liver failure, extracorporeal membrane oxygenation, reoperative exploration, and bleeding.

\section{Statistical Analysis}

Baseline characteristics were summarized by descriptive statistics composed of the mean \pm standard deviation and percentages. Differences between patient groups were analyzed using analysis of variance or $\chi^{2}$ tests. Unadjusted survival was performed using the Kaplan-Meier method with the log-rank test. Adjusted survival was calculated with a multivariable Cox regression adjusted for patient demographic characteristics, preoperative comorbidities, and LVAD complications within the month preceding transplant to determine differences in survival. The Cox proportional hazard tests were assessed the Schoenfeld residuals test. Hazard ratios (HRs) are presented with $95 \%$ confidence intervals (CIs). We also completed analysis of duration of BTT with an LVAD and the risk of death using LVAD time as a continuous variable. This allowed for analysis of BTT duration without artificially categorizing time points. This was completed using a restricted cubic spline model to analyze the variation of the hazard function on BTT duration compared with the survival of no BTT patients. 


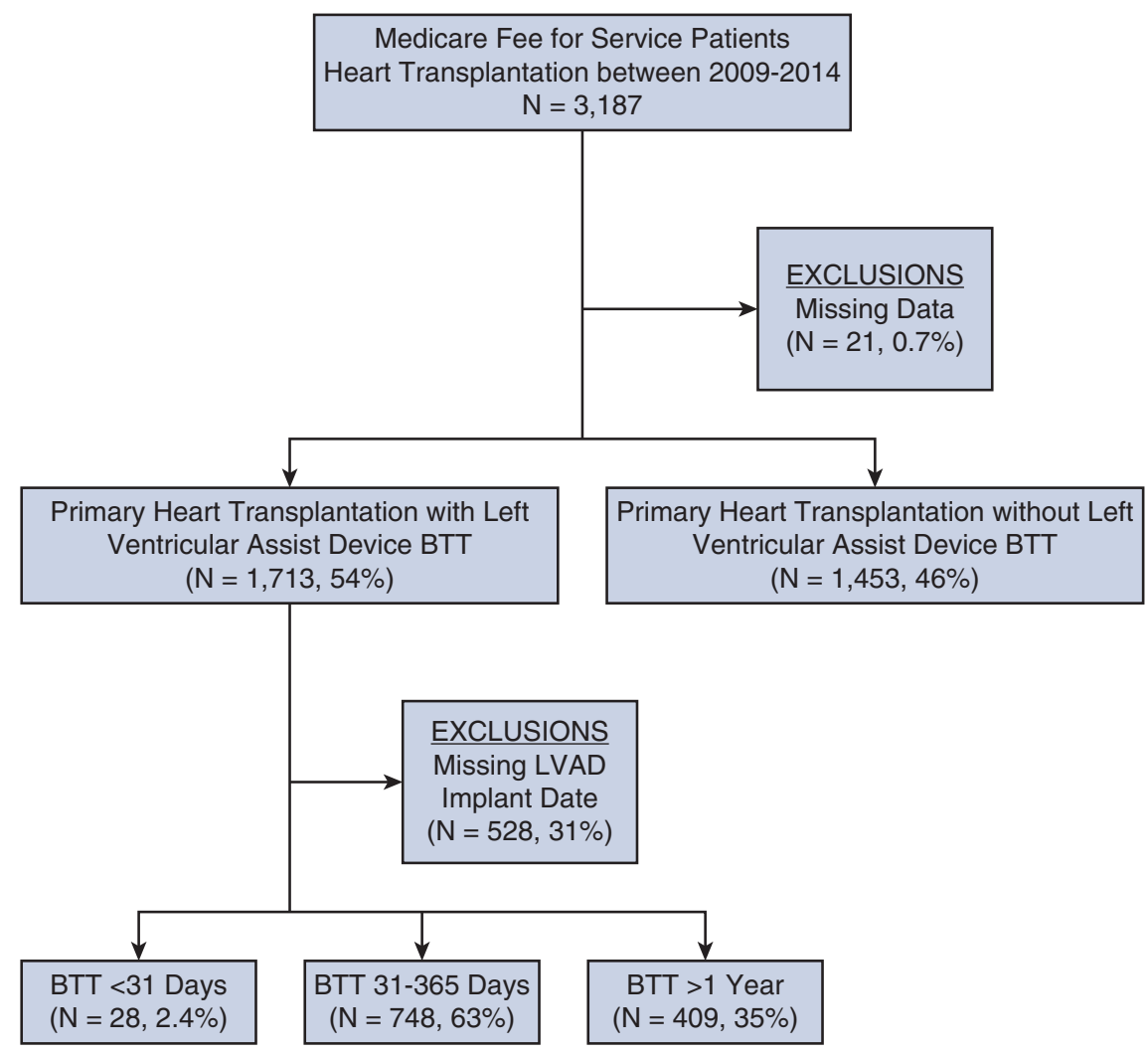

FIGURE 1. Flow chart of patient inclusion and exclusion criteria. BTT, Bridged to transplant; $L V A D$, left ventricular assist device.

Additionally, we calculated the adjusted cumulative incidence of postoperative complications and hospital readmissions for each patient group, using death as a competing risk. The Fine and Gray method was used to calculate the subdistribution HR and $P$ value for all competing risk models. All tests were 2-tailed with an alpha threshold of 0.05 . HRs and odds ratios are presented with $95 \%$ CIs. Statistical analyses were performed using Stata version 15.1 (StataCorp, College Station, Tex). Data management was performed using SAS version 9.3 (SAS Institute Inc, Cary, NC).

\section{RESULTS}

\section{Patients}

We identified 2639 primary Htx procedures from 2009 through 2014, with 1186 patients (45\%) BTT with an LVAD. Overall, LVAD patients were bridged for an average of $346.6 \pm 288.1$ days and a median of 265 days (interquartile range [IQR], 296 days). A histogram of LVAD BTT is presented in Figure E1. The BTT $<31$ days group had a mean LVAD duration of $15.8 \pm 9.3$ days, the BTT 31 to 365 days group had a mean LVAD duration of $192.9 \pm 86.6$ days, and the BTT $>365$ days group had a mean LVAD duration of $651.2 \pm 288.6$ days.

Table 1 presents patient characteristics before Htx and LVAD complications within 30-days before transplant for each group. Patients who were BTT with an LVAD had a tendency for increased comorbidities compared with no BTT patients. Patients who were BTT $<31$ days had the lowest overall LVAD complication rate of $14.3 \%$, followed by $40.2 \%$ for the BTT 31 to 365 days group, and at $44.7 \%$ for BTT $>365$ days group $(P<.005)$. For each specific complication, there were no significant differences for mechanical, pump thrombosis, local/systemic infections, or major bleeding among the BTT groups. The median follow-up time was 2.1 years (IQR, 3.8 years) for the BTT $<31$ days group, 2.3 years (IQR, 3.3 years) for the BTT 31 to 365 days group, 1.7 years (IQR, 2.5 years) for the BTT >365 days group, and 3.1 years (IQR, 1.54.5 years) for the no BTT group.

\section{Mortality after Htx}

Unadjusted all-cause mortality after Htx was significantly higher for patients BTT $<31$ days $(P=.018)$. Survival at 30 days was $81.5 \%$ for patients BTT $<31$ days, 94\% for patients BTT 31 to 365 days, 95\% for patients BTT $>365$ days, and $94 \%$ for no BTT. At 1 year, survival was $74 \%$ for patients BTT $<31$ days, $85 \%$ for patients BTT 31 to 365 days, $88 \%$ for patients BTT $>365$ days, and $89 \%$ for no BTT. At 3 years, survival was $65 \%$ for patients BTT $<31$ days, $78 \%$ for patients BTT 31 to 365 days, $81 \%$ for patients BTT $>365$ days, and $82 \%$ for no BTT (Figure 2).

In an adjusted multivariable Cox regression, survival at 3 years was significantly improved for BTT 31 to 
TABLE 1. Preoperative patient characteristics and presence of left ventricular assist device (LVAD) complications within 30-days before heart transplant

\begin{tabular}{|c|c|c|c|c|c|}
\hline Patient characteristic & $\begin{array}{c}\text { BTT }<31 \text { d } \\
(n=28)\end{array}$ & $\begin{array}{l}\text { BTT } 31-365 d \\
(n=748)\end{array}$ & $\begin{array}{c}\text { BTT }>365 d \\
(n=409)\end{array}$ & $\begin{array}{c}\text { No BTT } \\
(n=1453)\end{array}$ & $P$ value \\
\hline Age (y) & $60.5 \pm 9.4$ & $58.9 \pm 10.4$ & $57.6 \pm 11.5$ & $59.3 \pm 10.9$ & .034 \\
\hline Male & $20(71.4)$ & $613(82.0)$ & $325(79.5)$ & $1067(73.4)$ & $<.001$ \\
\hline White & $21(75.0)$ & $527(70.5)$ & $252(61.6)$ & $1042(71.7)$ & $<.001$ \\
\hline Ischemic cardiomyopathy & $23(82.1)$ & $609(81.4)$ & $265(64.8)$ & $969(66.4)$ & $<.0001$ \\
\hline Congenital & $7(25.0)$ & $164(21.9)$ & $35(8.6)$ & $206(14.2)$ & $<.0001$ \\
\hline Valvular disease & $21(75)$ & $6262(83.4)$ & $243(59.41)$ & $932(64.14)$ & $<.0001$ \\
\hline Hypertension & $20(71.4)$ & $626(83.7)$ & $303(74.1)$ & $1025(70.5)$ & $<.0001$ \\
\hline Diabetes & $14(50.0)$ & $398(53.2)$ & $185(45.2)$ & $594(40.9)$ & $<.0001$ \\
\hline Hypothyroidism & $5(17.9)$ & $154(20.6)$ & $90(22.0)$ & $265(18.2)$ & .29 \\
\hline Stroke & $8(28.6)$ & $203(27.1)$ & $92(22.5)$ & $219(15.07)$ & $<.001$ \\
\hline Pneumonia & $8(28.6)$ & $311(41.6)$ & $84(20.5)$ & $341(23.5)$ & $<.0001$ \\
\hline Chronic obstructive pulmonary disease & $8(28.6)$ & $309(41.3)$ & $98(24.0)$ & $423(29.1)$ & $<.0001$ \\
\hline Pulmonary circulation disease & $17(60.7)$ & $525(70.2)$ & 147 (35.9) & $746(51.34)$ & $<.0001$ \\
\hline Chronic kidney disease & $3(10.7)$ & $139(18.6)$ & $75(18.3)$ & $235(16.2)$ & .37 \\
\hline Hemodialysis pretransplant & $0(0.0)$ & $64(8.6)$ & $54(13.2)$ & $76(5.2)$ & $<.0001$ \\
\hline Peripheral vascular disease & $18(64.3)$ & $351(46.9)$ & $111(27.1)$ & $560(38.5)$ & $<.0001$ \\
\hline Protein-calorie malnutrition & $4(14.3)$ & 209 (27.9) & $43(10.5)$ & $141(9.7)$ & $<.001$ \\
\hline Obese & $3(10.7)$ & $97(12.9)$ & $56(13.7)$ & $113(7.8)$ & $<.0001$ \\
\hline Liver disease & $2(7.1)$ & $108(14.4)$ & $34(8.3)$ & $168(11.6)$ & .015 \\
\hline Coagulopathy & $28(39.3)$ & $313(41.8)$ & $108(26.4)$ & $281(19.3)$ & $<.0001$ \\
\hline Chronic blood loss anemia & $2(7.1)$ & $71(9.5)$ & $36(8.8)$ & $35(2.4)$ & $<.0001$ \\
\hline Major bleeding pretransplant & $18(64.3)$ & $504(67.4)$ & $231(56.5)$ & $440(30.3)$ & $<.0001$ \\
\hline Deficiency anemia & $11(39.3)$ & $500(66.8)$ & $206(50.4)$ & $573(39.4)$ & $<.0001$ \\
\hline Depression & $4(14.3)$ & $160(21.4)$ & $52(12.7)$ & $186(12.8)$ & $<.0001$ \\
\hline IABP pretransplant & $7(1.2)$ & $258(33.7)$ & $129(31.5)$ & $188(12.9)$ & $<.0001$ \\
\hline ECMO pretransplant & $1(3.5)$ & $20(2.7)$ & $16(3.9)$ & $6(0.4)$ & $<.0001$ \\
\hline \multicolumn{6}{|c|}{ LVAD complications within $30-\mathrm{d}$ of heart transplant } \\
\hline Any LVAD complication & $4(14.3)$ & $301(40.2)$ & $183(44.7)$ & NA & .005 \\
\hline Mechanical complications & $0(0)$ & 95 (12.7) & $58(14.2)$ & NA & .09 \\
\hline Pump thrombosis & $0(0)$ & $39(5.2)$ & $26(6.4)$ & NA & .31 \\
\hline Local/systemic infection & $1(3.6)$ & $69(9.2)$ & $50(12.2)$ & NA & .14 \\
\hline Any major bleeding event & $4(14.3)$ & $177(23.7)$ & 109 (26.7) & NA & .24 \\
\hline Gastrointestinal bleeding & $1(3.6)$ & $45(6.0)$ & $24(6.9)$ & NA & .86 \\
\hline Cerebral bleeding & $0(0)$ & $10(1.3)$ & $6(1.5)$ & NA & .28 \\
\hline Other major bleeding & $3(10.7)$ & $134(18.9)$ & $92(22.5)$ & NA & .13 \\
\hline
\end{tabular}

Values are presented as mean \pm standard deviation or $\mathrm{n}(\%) . B T T$, Bridged to transplant; IABP, intra-aortic balloon pump; $E C M O$, extracorporeal membrane oxygenation; $L V A D$, left ventricular assist device; $N A$, not available.

365 days (HR, 0.4; 95\% CI, 0.21-0.82; $P=.012$ ), BTT $>365$ days (HR, $0.39 ; 95 \% \mathrm{CI}, 0.19-0.80 ; P=.010$ ), and no BTT groups (HR, 0.46; 95\% CI, 0.23-0.91; $P=.025$ ) compared with BTT $<31$ days. Risk factors for death at 3 years was associated with pretransplant renal insufficiency (HR, 1.25; 95\% CI, 1.02-1.56; P .034), pneumonia
(HR, 1.64; 95\% CI, 1.34-2.01; $P<.001$ ), and any major bleeding event at 30 days before transplant (HR, 2.07; $95 \%$ CI, 1.22-3.53; $P<.007)$. Table E4 shows the multivariable Cox regression.

Similarly, risk factors associated with death at 30 days after HTx were significant for renal insufficiency (HR, 1.39; 


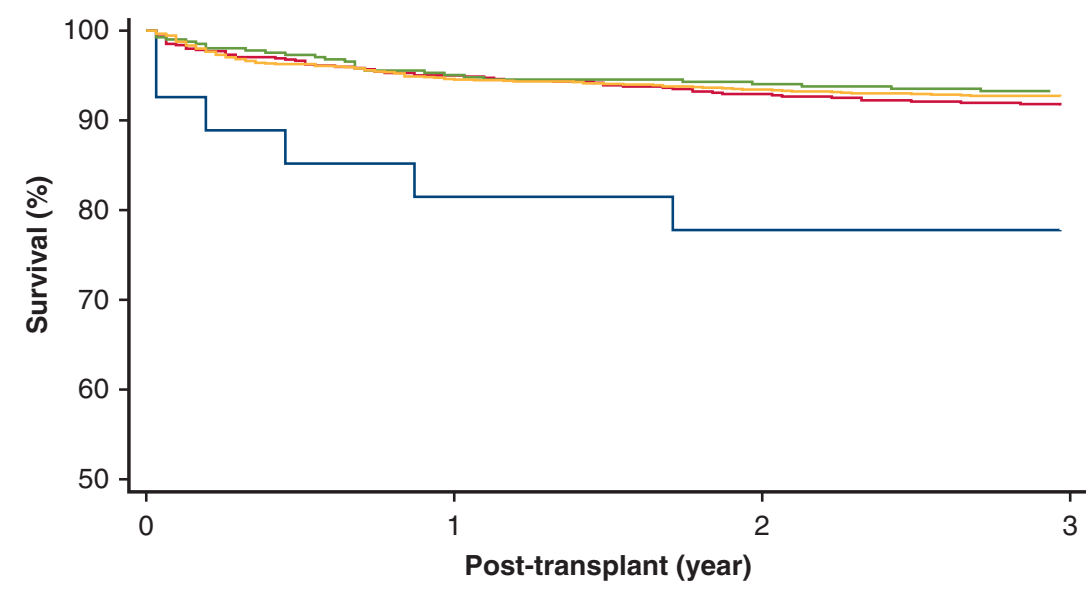

Number at Risk

Bridge to Transplant

\begin{tabular}{|c|c|c|c|c|}
\hline$<31$ days & 28 & 20 & 14 & 11 \\
\hline $31-365$ days & 749 & 524 & 401 & 305 \\
\hline$>365$ days & 409 & 270 & 175 & 107 \\
\hline \multicolumn{5}{|c|}{ No Bridge to Transplant } \\
\hline & 1453 & 1179 & 1026 & 759 \\
\hline
\end{tabular}

FIGURE 2. Survival after heart transplantation based on bridge to transplant (BTT) duration with a left ventricular assist device. The $95 \%$ confidence intervals for survival can be found in Table E1.

95\% CI, 1.08-1.70; $P<.032$ ), pneumonia (HR, $1.53 ; 95 \%$ CI, 1.07-2.21; $P<.02$ ), and having any major bleeding event at 30 days before transplant (HR, 3.37; 95\% CI, $1.27-8.93 ; P<.02)$.

The duration of BTT with an LVAD was also analyzed as a continuous variable (Figure 3). Patients that underwent BTT had statistically increased adjusted mortality when LVAD BTT timing was between 4 and 34 days before HTx. During this early time period, risk of death was up to $50 \%$ higher. As seen in Figure 2, this was the only period

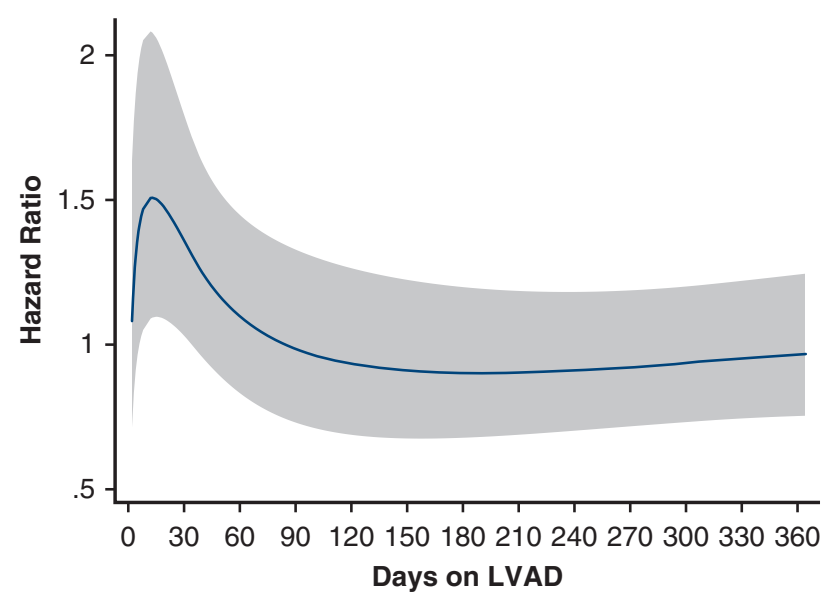

FIGURE 3. Hazard ratio for mortality after heart transplantation based on bridge to transplant duration with a left ventricular assist device (LVAD). when the HR and 95\% CIs were all $>1$ (shaded area), indicating statistically increased mortality.

\section{Complications}

The cumulative incidences of posttransplant complications are presented at 30 days (Table 2) and at 1 year (Table 3). Thirty days after transplant, both the BTT 31 to 365 days and BTT $>365$ days groups had a lower incidence of tracheostomy and need for hemodialysis compared with the BTT $<31$ days group. Additionally, the BTT 31 to 365 days group had a lower incidence for sepsis, acute kidney injury, and postoperative bleeding compared with BTT $<31$ days patients. We found no other differences between the other complications listed in Table 2 at 30 days.

At 1 year posttransplant, the cumulative incidence for hemodialysis and postoperative bleeding were significantly lower in both BTT 31 to 365 days and BTT $>365$ days groups, compared with the BTT $<31$ days group (Table $3)$. Additionally, acute kidney injury was lower in patients BTT 31 to 365 days when compared with BTT $<31$ days.

The median length of stay was 42.5 days (IQR, 34.5 days) for BTT $<31$ days, 16 days (IQR, 18 days) for BTT 31 to 365 days, and 16 for BTT $>365$ days $(P=.002)$.

\section{All-cause Hospital Readmissions}

We calculated the cumulative incidence for hospitalization readmissions and found that patients BTT $>365$ days had the highest greatest incidence of hospital readmissions. 
TABLE 2. Cumulative incidence of posttransplant complications at 30 days

\begin{tabular}{|c|c|c|c|c|c|c|c|}
\hline Complication & BTT $<31$ d & $\begin{array}{c}\text { BTT } \\
31-365 \text { d }\end{array}$ & BTT $>365$ d & $\begin{array}{l}\text { BTT 31-365 d } \\
\text { SHR }(95 \% \text { CI) }\end{array}$ & $P$ value* & $\begin{array}{c}\text { BTT }>365 \text { d } \\
\text { SHR }(95 \% \text { CI })\end{array}$ & $P$ value* \\
\hline Stroke & 12 & 7.2 & 8.1 & $0.57(0.21-1.60)$ & .29 & $0.62(0.21-1.85)$ & .39 \\
\hline Pneumonia & 8.3 & 15 & 21 & $2.30(0.54-9.64)$ & .26 & $3.03(0.72-12.72)$ & .13 \\
\hline Pulmonary embolism & 2.0 & 1.5 & 1.9 & $0.59(0.06-5.8)$ & .66 & $0.81(0.07-9.35)$ & .87 \\
\hline Tracheostomy & 13 & 4.8 & 5.0 & $0.27(0.08-0.89)$ & .03 & $0.29(0.1-0.92)$ & .04 \\
\hline Sepsis & 15 & 4.8 & 8.2 & $0.28(0.10-0.83)$ & .021 & $0.51(0.17-1.47)$ & .22 \\
\hline Acute kidney injury & 58 & 39 & 48 & $0.58(0.36-0.94)$ & .018 & $0.74(0.46-1.23)$ & .25 \\
\hline Hemodialysis & 29 & 9.5 & 13 & $0.29(0.13-0.69)$ & .004 & $0.35(0.15-0.85)$ & .021 \\
\hline Liver failure & 4.1 & 6.5 & 5.2 & $1.62(0.22-12.00)$ & .63 & $1.45(0.18-11.57)$ & .73 \\
\hline Extracorporeal membrane oxygenation & 2.4 & 1.3 & 1.8 & $0.49(0.05-5.29)$ & .56 & $0.73(0.07-7.68)$ & .79 \\
\hline Re-exploration & 16 & 7.9 & 9.2 & $0.43(0.15-1.24)$ & .12 & $0.51(0.17-1.54)$ & .23 \\
\hline Bleeding & 36 & 16 & 15 & $0.48(0.25-0.94)$ & .031 & $0.45(0.22-0.89)$ & .23 \\
\hline
\end{tabular}

Values are presented as \% or subdistribution hazard ratio ( $95 \%$ confidence interval). BTT, Bridged to transplant; SHR, subdistribution hazard ratio; $C I$, confidence interval.

*Determined by Fine and Gray test.

At 1 year after HTx, the cumulative incidence was $26 \%$ for BTT 31 to 365 days group, $33 \%$ for BTT $>365$ days (HR, $1.37 ; 95 \%$ CI, $1.06-1.77 ; P=.015), 14.3 \%$ for BTT $<31$ days (HR, $0.53 ; 95 \% \mathrm{CI}, 0.17-1.76 ; P=.30$ ), and $17.8 \%$ for no BTT patients (HR, 0.67; 95\% CI, 0.53$0.83 ; P=.001)$. Only preoperative pneumonia (HR, 1.43 ; $95 \%$ CI, $1.1-1.71 ; P=.005)$ and anemia $(\mathrm{HR}, 1.35 ; 95 \%$ CI, 1.13-1.72; $P=.01$ ) were associated with increased risk for 1-year hospital readmissions.

\section{DISCUSSION}

In our study, we used Medicare data from 2009 to 2014 to investigate outcomes of patients BTT with an LVAD compared with patients who went directly to HTx. The goal of this study was to determine whether there existed an optimal time period during BTT LVAD support when survival was superior with fewest complications. First, patients BTT with an LVAD had similar all-cause mortality compared with no BTT patients at 3 years' follow-up. Second, when patients are dichotomized based on timing of BTT, patients who underwent transplant within the first month of LVAD implant had a significant increase in allcause mortality. Patients transplanted during this early time period had up to a $50 \%$ increase in the risk for death. However, we found no survival difference between patients who were BTT 31 to 365 days or BTT $>365$ days. It is important to note that the survival analyses took into consideration if patients had any LVAD-related complications within 30 days preceding transplantation.

The question of optimal BTT duration has been previously examined. Most recently, Grimm and colleagues ${ }^{11}$ investigated 1332 patients BTT with an LVAD using United

TABLE 3. Cumulative incidence of posttransplant complications at 1 year

\begin{tabular}{|c|c|c|c|c|c|c|c|}
\hline Complication & BTT $<31$ d & BTT 31-365 d & BTT $>365 d$ & $\begin{array}{l}\text { BTT 31-365 d } \\
\text { SHR }(95 \% \text { CI })\end{array}$ & $P$ value* & $\begin{array}{c}\text { BTT }>365 \text { d } \\
\text { SHR }(95 \% \text { CI })\end{array}$ & $P$ value* \\
\hline Stroke & 23 & 14 & 15 & $0.57(0.21-1.60)$ & .29 & $0.62(0.21-1.85)$ & .39 \\
\hline Pneumonia & 29 & 32 & 36 & $2.30(0.54-9.64)$ & .26 & $3.03(0.72-12.72)$ & .13 \\
\hline Pulmonary embolism & 8.2 & 4.2 & 5.8 & $0.59(0.06-5.8)$ & .66 & $0.81(0.07-9.35)$ & .87 \\
\hline Tracheostomy & 13 & 4.8 & 6.3 & $0.27(0.08-0.89)$ & .03 & $0.29(0.1-0.92)$ & .04 \\
\hline Sepsis & 18 & 16 & 20 & $0.28(0.10-0.83)$ & .021 & $0.51(0.17-1.47)$ & .22 \\
\hline Acute kidney injury & 76 & 54 & 60 & $0.58(0.36-0.94)$ & .018 & $0.74(0.46-1.23)$ & .25 \\
\hline Hemodialysis & 32 & 13 & 15 & $0.29(0.13-0.69)$ & .004 & $0.35(0.15-0.85)$ & .021 \\
\hline Liver failure & 7.2 & 11 & $9 \%$ & $1.62(0.22-12.00)$ & .63 & $1.45(0.18-11.57)$ & .73 \\
\hline Extracorporeal membrane oxygenation & 2.6 & 2.1 & 3.7 & $0.49(0.05-5.29)$ & .56 & $0.73(0.07-7.68)$ & .79 \\
\hline Re-exploration & 17 & 9.1 & 10 & $0.43(0.15-1.24)$ & .12 & $0.51(0.17-1.54)$ & .23 \\
\hline Bleeding & 49 & 31 & 29 & $0.48(0.25-0.94)$ & .031 & $0.45(0.22-0.89)$ & .23 \\
\hline
\end{tabular}

Values are presented as $\%$ or subdistrbution hazard ratio ( $95 \%$ confidence interval). BTT, Bridge to transplant; $S H R$, subdistribution hazard ratio; $C I$, confidence interval. *Determined by Fine and Gray test. 
Network for Organ Sharing data from 2011 to 2012. ${ }^{11}$ BTT patients were grouped into $<90$ days, 90 to 365 days, and $>365$ days groups. No survival difference was detected among any of the groups at 30 days or 1 year posttransplant. Although postoperative complications were not present in the United Network for Organ Sharing database and could not be evaluated, the investigators analyzed functional outcomes of patients using the Karnofsky performance scale. They found that patients with increased BTT length ( $>90$ days) had the greatest increase in functional performance while on the waiting list. However, if a patient had BTT length $>90$ days but poor functional performance at the time of HTx, posttransplant mortality was increased in this subgroup. In another study, John and colleagues ${ }^{12}$ evaluated data from the HeartMate II trial from 2005 to 2008 and presented BTT data for 250 patients who eventually underwent transplant. At 1 year posttransplant, no survival differences were detected in groups BTT $<30$ days, 30 to 90 days, 90 to 179 days, or 180 days or longer. At 1 year after transplantation, survival was $94 \%$ for BTT duration $<30$ days, $93 \%$ for BTT duration 30 to 89 days, and $84 \%$ for BTT duration 90 to 179 days $(P=.18)$. Due to the small sample size in each group and limited follow-up data, survival was only analyzed at 1 year after transplant. Other studies that have investigated BTT timing are not generalizable to the modern era because patients were transplanted from 1999 to 2006 and were primarily bridged with pulsatile devices. ${ }^{13,14,18,19}$

Our study is complementary to these investigations but provides new insights. First, we have 6 years of recent data (to 2014). Because there is longer follow-up than in previous studies, we have presented survival up to 3 years posttransplant and have shown no differences among groups. Second, because Medicare data were used, we were able to analyze perioperative complications and hospital readmissions. These outcomes have never been evaluated in recent reports. Third, we have compared BTT patients with nonbridged patients. We believe that due to the scarcity of donor hearts, it is critical to also determine whether timing of BTT has a deleterious influence on survival compared with no BTT. And finally, we evaluated BTT duration as a continuous variable and confirmed that survival is only worse if BTT duration is less than approximately 1 month. The benefit of this approach is that duration of BTT is not categorized into artificial groups.

We discovered that patients BTT $<31$ days had very poor survival. Among patients transplanted within 31 days of BTT, only $81.5 \%$ were alive at 30 days and only $74.1 \%$ were alive at 1 year. When BTT time was analyzed as a continuous variable, patients transplanted between 4 and 34 days after LVAD insertion had up to $50 \%$ greater risk of death than other patients. However, there were only 28 out of 1186 patients $(2.4 \%)$ who underwent transplant during this early time period. It appears that practice patterns have changed significantly over the past decade because we found that few patients undergo transplant immediately after LVAD implantation in the current era.

Smedira and colleagues ${ }^{14}$ evaluated outcomes in patients from 1991 to 2006, using single institution data on 375 patients who were BTT with an LVAD. Forty-four patients $(17 \%)$ were transplanted with BTT times $<30$ days. Exact survival percentages in this early group were not provided, but predicted survival among all BTT patients revealed no mortality increase during the first 30 days. However, almost all patients had pulsatile pumps during this study. Only in the study by John and colleagues that was discussed previously, ${ }^{12}$ is BTT timing $<30$ days presented among patients with continuous flow devices. They investigators found no detriment in survival among patients BTT $<30$ days. However, the data they analyzed were from the HeartMate II pivotal trial, and all patients had advanced heart failure but without evidence of multiorgan failure. These patients were all carefully selected and possibly not reflective of real-world practice. We specifically investigated $<31$ days on LVAD as a time point in our study because we expected these patients to undergo HTx due to early LVAD complications and would likely have increased perioperative mortality. However, we found that this early group had the lowest proportion of LVAD complications within the month preceding HTx. Regardless, using more recent data, we determined that very few patients are undergoing transplantation within the first 30 days of bridging with an LVAD. Although we cannot determine the Interagency Registry for Mechanically Assisted Circulatory Support profile of the patients who underwent early transplantation, the poor survival in this group suggests caution is necessary before proceeding. In the study by Attisani and colleagues, ${ }^{9}$ LVAD therapy is a successful bridge to temporize critically ill patients with multiorgan failure so that HTx can be completed electively. During this early period, patients who are recovering from cardiogenic shock and multiorgan injury after LVAD implantation should recover before transplant procedures are undertaken.

This study was conducted in the modern era of continuous flow devices. The durability of continuous flow LVADs have dramatically improved durability compared with the early pulsatile devices, and this has allowed patients to remain for longer duration on LVAD support. In our study, $34 \%$ of all BTT patients were transplanted after 365 days of support without an increase in all-cause mortality or complications. However, this group had an increased incidence of hospital readmissions compared with BTT duration of 31 to 365 days. Reasons for this increase in hospital readmissions are not explainable with this dataset. 


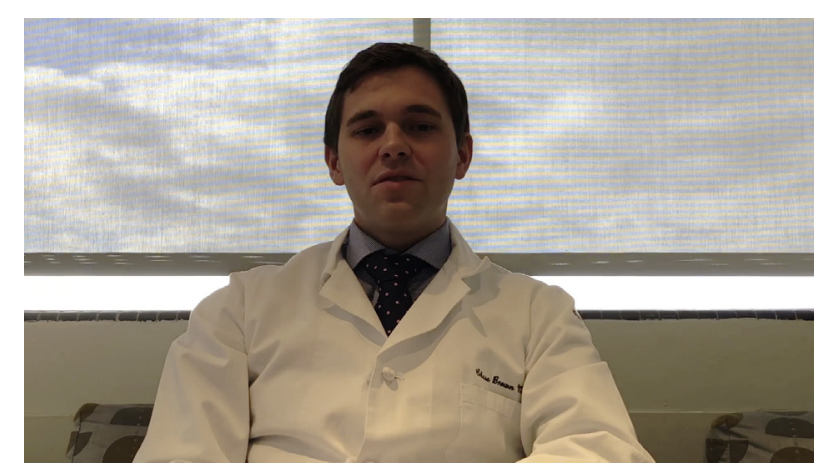

VIDEO 1. Video contribution from authors explaining significance of study. Video available at: https://www.jtcvs.org/article/S0022-5223(19) 30539-2/fulltext.

This study has several limitations. First, Medicare feefor-service patients were analyzed and represent an older cohort of patients requiring HTx. Although longitudinal analysis of these patients is robust, it comprises $<50 \%$ of all patients undergoing HTx in the United States and may not be generalizable to all patients undergoing HTx. Additionally, analyses using administrative claims data are subject to coding errors and lack important clinical variables such as listing status (United Network for Organ Sharing $1 \mathrm{~A}$ or 1B status), laboratory data, LVAD device model information, and operative characteristics. Medicare data lack donor details, and we were unable to incorporate this into the multivariate analysis. It is possible that this could influence outcomes across groups. Another limitation is the inability to determine whether Medicare patients with an LVAD are BTT or destination therapy at time of LVAD implant. For this reason, BTT candidates could only be identified as LVAD patients who eventually underwent HTx. Thus, we were unable to analyze the mortality of LVAD BTT patients before transplantation. This has likely produced selection bias among the BTT groups because the people who underwent transplant were highly selected and survived to transplantation. Lastly, this study examined patients who underwent a surgical LVAD implantation, and should not be generalized to patients who are placed on extracorporeal membrane oxygenation or a temporary, percutaneous LVAD.

\section{CONCLUSIONS}

BTT with an LVAD is a suitable strategy to temporize patients with end-stage heart failure. We have found that patients who are BTT with an LVAD and then undergo transplant within the first month have an increased risk for mortality and perioperative complications. Additional caution is necessary before scheduling patients for transplant within this early time period. However, there were no survival differences among patients who were BTT with an LVAD $>31$ days before transplant (Video 1).

\section{Webcast}

You can watch a Webcast of this AATS meeting presentation by going to: https://aats.blob.core.windows.net/ media/18May01/23BC\%203.MCS\%20Transplant/S96_1_ webcast_040407381.mp4.

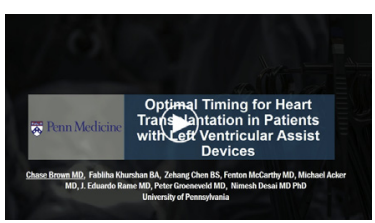

\section{Conflict of Interest Statement}

Authors have nothing to disclose with regard to commercial support.

\section{References}

1. Benjamin EJ, Blaha MJ, Chiuve SE, Cushman M, Das SR, Deo R, et al. Heart disease and stroke statistics-2017 update: a report from the American Heart Association. Circulation. 2017;135:e146-603.

2. Kirklin JK, Naftel DC, Kormos RL, Stevenson LW, Pagani FD, Miller MA, et al. The Fourth INTERMACS annual report: 4,000 implants and counting. J Heart Lung Transplant. 2012;31:117-26.

3. Alba AC, McDonald M, Rao V, Ross HJ, Delgado DH. The effect of ventricular assist devices on long-term post-transplant outcomes: a systematic review of observational studies. Eur J Heart Fail. 2011;13:785-95.

4. Stehlik J, Edwards LB, Kucheryavaya AY, Benden C, Christie JD, Dobbels F, et al. The registry of the International Society for Heart and Lung Transplantation: twenty-eighth adult heart transplant report-2011. J Heart Lung Transplant. 2011;30:1078-94.

5. Slaughter MS, Rogers JG, Milano CA, Russell SD, Conte JV, Feldman D, et al. Advanced heart failure treated with continuous-flow left ventricular assist device. N Engl J Med. 2009;361:2241-51.

6. Kitada S, Schulze PC, Jin Z, Clerkin K, Homma S, Mancini DM. Comparison of early versus delayed timing of left ventricular assist device implantation as a bridge-to-transplantation: an analysis of the UNOS dataset. Int $J$ Cardiol. 2016;203:929-35.

7. Schumer EM, Ising MS, Trivedi JR, Slaughter MS, Cheng A. Early outcomes with marginal donor hearts compared with left ventricular assist device support in patients with advanced heart failure. Ann Thorac Surg. 2015;100:522-7.

8. Sorabella RA, Yerebakan H, Walters R, Takeda K, Colombo P, Yuzefpolskaya M, et al. Comparison of outcomes after heart replacement therapy in patients over 65 years old. Ann Thorac Surg. 2015;99:582-8.

9. Attisani M, Centofanti P, La Torre M, Boffini M, Ricci D, Ribezzo M, et al. Advanced heart failure in critical patients (INTERMACS 1 and 2 levels): ventricular assist devices or emergency transplantation? Interact Cardiovasc Thorac Surg. 2012; 15:678-84.

10. Theochari CA, Michalopoulos G, Oikonomou EK, Giannopoulous S, Doulamis IP, Villela MA, et al. Heart transplantation versus left ventricular assist devices as destination therapy or bridge to transplantation for 1-year mortality: a systematic review and meta-analysis. Ann Cardiothorac Surg. 2018;7:3-11.

11. Grimm JC, Magruder JT, Crawford TC, Fraser CD III, Plum WG, Sciortino CM, et al. Duration of left ventricular assist device support does not impact survival after US heart transplantation. Ann Thorac Surg. 2016;102:1206-12.

12. John R, Pagani FD, Naka Y, Boyle A, Conte JV, Russell SD, et al. Post-cardiac transplant survival after support with a continuous-flow left ventricular assist device: impact of duration of left ventricular assist device support and other variables. J Thorac Cardiovasc Surg. 2010;140:174-81.

13. Gammie JS, Edwards LB, Griffith BP, Pierson RN III, Tsao L. Optimal timing of cardiac transplantation after ventricular assist device implantation. J Thorac Cardiovasc Surg. 2004;127:1789-99.

14. Smedira NG, Hoercher KJ, Yoon DY, Rajeswaran J, Klingman L, Starling RC, et al. Bridge to transplant experience: factors influencing survival to and after cardiac transplant. J Thorac Cardiovasc Surg. 2010;139:1295-305. 
15. Elixhauser A, Steiner C, Harris DR, Coffey RM. Comorbidity measures for use with administrative data. Med Care. 1998;36:8-27.

16. Li B, Evans D, Faris P, Dean S, Quan H. Risk adjustment performance of Charlson and Elixhauser comorbidities in ICD-9 and ICD-10 administrative databases. BMC Health Serv Res. 2008;8:12.

17. Tripathi B, Arora S, Kumar V, Thakur K, Lahewala S, Patel N, et al. Hospital complications and causes of 90-day readmissions after implantation of left ventricular assist devices. Am J Cardiol. 2018;122:420-30.

18. Schmid C, Welp H, Klotz S, Baba HA, Wilhelm MJ, Scheld HH. Outcome of patients surviving to heart transplantation after being mechanically bridged for more than 100 days. J Heart Lung Transplant. 2003;22:1054-8.

19. Robertson JO, Lober C, Smedira NG, Navia JL, Sopko N, GonzalezStawinski GV. One hundred days or more bridged on a ventricular assist device and effects on outcomes following heart transplantation. Eur J Cardiothorac Surg. 2008;34:295-300.

Key Words: LVAD, survival, heart transplant, bridge to transplant, outcomes research, health policy research

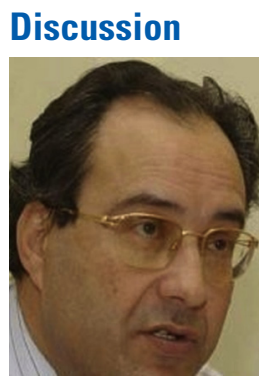

\section{Dr Manuel Antunes (Coimbra,}

Portugal). I would like to thank the Association for the privilege of discussing this interesting paper. Dr Brown, I enjoyed your short presentation and thank you for sending me the manuscript in advance.

You and your colleagues wanted to determine the effect of duration-not timing, timing is the word that you use in the manuscript — of left ventricular device bridging to transplantation on postoperative heart transplant outcomes, reviewing the available data of more than 2500 Medicare patients who underwent heart transplant using a primary end point of overall survival and dividing into $<1$ year and $>1$ year of assistance compared with patients who did not have assistance before transplantation.

I suggest 2 or 3 aspects because they will generate my questions. Early mortality was equal amongst the groups, and you found that at 3 years adjusted survival was similar between groups, so no difference with regard to survival. All your patients who underwent transplant within 34 days of bridging were at a significantly increased risk of death, but patients bridged beyond 1 year had an increased risk of postoperative complications and a significantly increased risk for hospital readmission at 1 year. Those are the main conclusions as I see them.

I think this is an important study with similar data from other reports, although yours used a longer follow-up, which is really important. In an area where there is an increasing shortage of donors, bridging is the only salvation for many patients.

Although Medicare patients who at present are an older cohort of heart transplantation patients, I believe that your sample still represents the whole population. However, because of the administrative data, you acknowledge that there were a lot of missing data that would be important, especially the clinical. There were a lot of difference among these 3 groups, and this may confuse a little bit the conclusions. Therefore, one must be careful about deriving conclusions on these otherwise excellent results.

One comment I want to make is that unfortunately left ventricular assist device is not available elsewhere in the world as easily as it appears to be in the United States judging from the number of patients, and I noticed that you excluded from this study patients who were bridged with other devices such as extracorporeal circulation and so on, and those are the devices that the common people in the real world use more frequently. It would have been important to know if there was any influence between the different types of devices, and you say these administrative data did not have sufficient information.

However, and this is my question, did you or could you have access to any data that would allow you to say what type of devices was better in this type, having in mind that in the 6 years' duration of this study there have been a lot of changes in this respect. You did not put it in the article, but do you have any feeling about it?

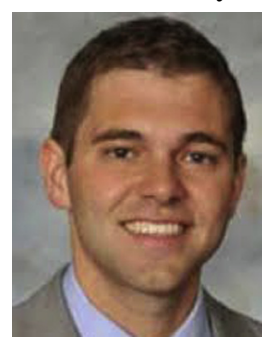

Dr Chase R. Brown (Philadelphia, $\mathrm{Pa}$ ). In terms of the types of devices that were actually used, like a circulatory versus pulsatile type devices?

Dr Antunes. Yes.

Dr Brown. Unfortunately, the way that Medicare is coded out, these procedural codes are not specific enough to actually tell you the type of device that is actually used, and that's another limitation of the study. Because a lot of the studies that looked at this previously looked at studies that were mixed with pulsatile devices and circulatory devices, I think that because they were mixed, some of the outcomes weren't as applicable to the time frame now, when the majority of the devices are nonpulsatile. But that's really the only granular information that you can get out of a Medicare database, unless you could do it within the United Network for Organ Sharing database, but we didn't have access to that.

Dr Antunes. I can't understand why the short-term assisted patients had worse outcomes, in fact in the early days, because those patients were very unstable and had organ failure, and that is easy to understand. Why would patients who have been on bridging for more than a year have so many more complications than those who were less than a year? And of course if you are at 364 days, you end up in 1 group; if you are 366 days, you end up in the other group. Was there a continuum or was there a difference, and what are the causes for that?

Dr Brown. That's why we originally wanted to do it as a continuous variable like we did with showing the hazard of time. We did not do that with complications, but I think it would be a good idea, because I think, again, it's an artificial 
cutoff at 365 days. So to do that and to look at the rate of complications with a hazard, I think it probably would be more appropriate to see if there is an inflection point.

To be honest, I don't have a good explanation, a mechanistic explanation, of why patients who were bridged the longest had more complications, because they were also the patients who looked, at least on the comorbidities, that they were not the sickest. They were actually less sick than people who were bridged younger.

When I was talking to cardiologists about this, their thinking whether or not having a nonpulsatile device, how that influences end-organ outcomes, I don't know. Those are completely hypothesizing to explore.

Dr Antunes. Because these causes for readmission were not really directly related to the device.

Dr Brown. No, because that is all after the transplant. These were readmissions after transplantation.

Dr Antunes. Okay, thank you. Once again, congratulations on good work and a nice presentation.

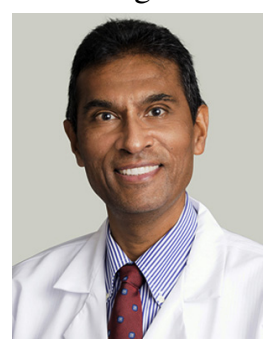

Dr Valluvan Jeevanandam (Chicago, Ill). Perhaps the answer to that question is how did those patients who were there for more than a year actually get transplanted? A lot of them end up getting transplanted because they get urgent status as $1 \mathrm{~A}$ because they actually have a complication. So they might have had infection, stroke, device malfunction, or gastrointestinal bleeding, which could cause issues, stuff like that. So maybe that may answer that question.

Dr Brown. Some of that information we could get from the Medicare database.

Dr Jeevanandam. I don't know if it is in the Medicare database, like were they transplanted as United Network for Organ Sharing status 1A or 1B.
Dr Brown. Yes, that wouldn't be, but we could see the timing of their transplantation after maybe a readmission for a diagnosis code. So if they came in for sepsis or for stroke, we would be able to then see their time from that hospitalization until transplantation.

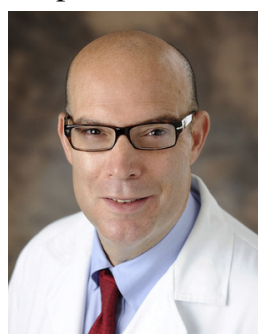

Dr Scott C. Silvestry (Orlando, Fla). I have a comment. To echo Dr Jeevanandam's statement, I think the trouble with this type of analysis in addition to the artificiality of 1 year is that we don't code very well why that patient was transplanted at that moment, and device-related complications are probably the bigger driver, or social things. We have many patients who are bridged to transplant but they are waiting for them to quit smoking or do other things like that, or they are raising funds, and it is so difficult to figure out why they were listed at that moment or got transplanted at that moment.

Some of it is coded in the United Network for Organ Sharing data set that you can look that they had device malfunction at the time of transplant, but it's a difficult thing to tease out from that. I am curious, this is Medicare data?

Dr Brown. Yes.

Dr Silvestry. And yet the average age of your recipients was in the 50s. That's pretty young for a Medicare population.

Dr Brown. The way you can get on Medicare is being older than age 65 years, but you can also get into Medicare by having a disability for 2 years and then get put on Medicare.

Dr Silvestry. It's an interesting social statement for US health care that that's how we are getting these people on Medicare. 


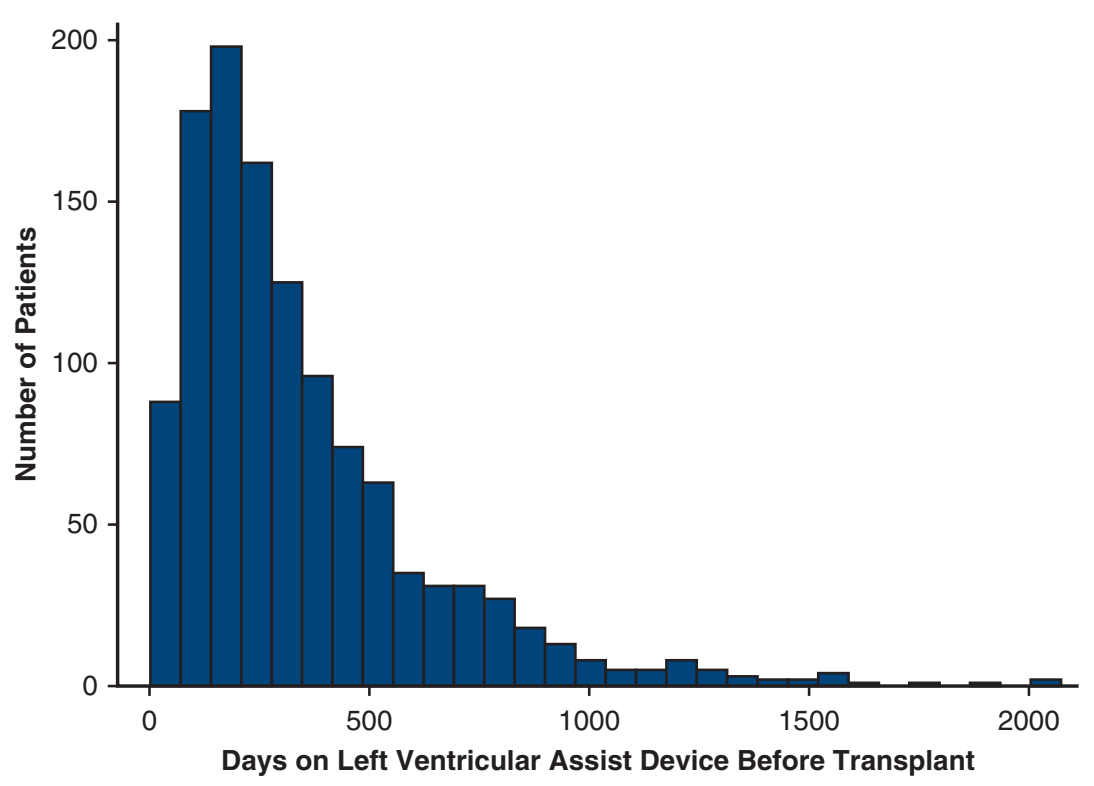

FIGURE E1. A histogram of patients bridged to transplant with a left ventricular assist device.

TABLE E1. Overall survival of patients at each time point with $95 \%$ confidence intervals for heart transplant patients stratified by the presence of a bridge to transplant (BTT) left ventricular assist device

\begin{tabular}{lccr}
\hline & $\mathbf{3 0} \mathbf{d}$ & $\mathbf{1 ~ y}$ & $\mathbf{3} \mathbf{~}$ \\
\hline BTT $<31 \mathrm{~d}$ & $0.81(0.61-0.91)$ & $0.74(0.53-0.86)$ & $0.65(0.44-0.80)$ \\
BTT 31-365 d & $0.94(0.92-0.96)$ & $0.85(0.83-0.88)$ & $0.78(0.76-0.82)$ \\
BTT $>365$ d & $0.95(0.93-0.97)$ & $0.88(0.85-0.92)$ & $0.81(0.76-0.85)$ \\
No BTT & $0.94(0.93-0.96)$ & $0.89(0.86-0.90)$ & $0.82(0.79-0.84)$ \\
\hline
\end{tabular}

BTT, Bridge to transplant. 
TABLE E2. International Classification of Diseases ninth revision (ICD-9) and Current Procedural Terminology (CPT) codes for patient characteristics and comorbidities

\begin{tabular}{|c|c|c|c|}
\hline Comorbidity & ICD-9 diagnosis codes & $\begin{array}{l}\text { ICD-9 procedure } \\
\text { code }\end{array}$ & CPT codes \\
\hline $\begin{array}{l}\text { Left ventricular assist } \\
\text { device insertion }\end{array}$ & V4321 & 3766 & 3397933975 \\
\hline $\begin{array}{l}\text { Left ventricular assist } \\
\text { device removal }\end{array}$ & & & 3397733980 \\
\hline Hypertension & $\begin{array}{l}40104011401940200402014021040211 \\
402904029140300403014031040311 \\
403904039140400-4040340410-40413 \\
40490404914049240493 \\
405014050940511405194059140599 \\
437264200-6420464210-6421464220- \\
6422464270-6427464290-64294\end{array}$ & & \\
\hline Congestive heart failure & $398914280-4289$ & & \\
\hline Peripheral vascular disease & $\begin{array}{l}\text { 4400-4409 44100-4419 4420-4429 } 4431 \\
\text {-4439 44421-44422 } 447144955715579 \\
\text { V434 }\end{array}$ & & \\
\hline $\begin{array}{l}\text { Chronic obstructive pulmonary } \\
\text { disease }\end{array}$ & $\begin{array}{l}490491049114912491204912149122 \\
491849194920492849449404941496\end{array}$ & & \\
\hline Renal failure & $\begin{array}{l}58535854585558565859586 \text { V420 V451 } \\
\text { V560 -V5632 V568 V4511-V4512 }\end{array}$ & & \\
\hline Chronic kidney disease & 585585958515852585358545855 & & \\
\hline Hemodialysis & $\begin{array}{l}403014031140391404024040340412 \\
4041340492404935856 \text { V451 V4511 } \\
\text { V4512 V560 V561 V5631 }\end{array}$ & 3995 & 909259093590937909459094790999 \\
\hline Liver disease & $\begin{array}{l}070220702307032070330704407054 \\
456045614562045621571057125713 \\
57140-571495715-5719572357285735 \\
\text { V427 }\end{array}$ & & \\
\hline Diabetes & $\begin{array}{l}24900-2493124940-2499125000-25033 \\
25040-2509364800-648047751\end{array}$ & & \\
\hline Metastatic cancer & $1960-199120970-209752097978951$ & & \\
\hline Dementia & $\begin{array}{l}29002901029011290122901329020 \\
29021290329040290412904229043 \\
940294129410294112942029421 \\
3311933182\end{array}$ & & \\
\hline Protein-calorie malnutrition & 26382639 & & \\
\hline Pulmonary Hypertension & 41604168 & & \\
\hline Ischemic cardiomyopathy & $\begin{array}{c}4149414841004100041001410024101 \\
41010410114101241024102041021 \\
4102241034103041031410324104 \\
41040410414104241054105041051 \\
4105241064106041061410624107 \\
41070410714107241084108041081 \\
410824109410904109141092\end{array}$ & & \\
\hline Congenital & $\begin{array}{c}74507451074511745127451974527453 \\
7454745574560745617456974577458 \\
7459746007460174602746097461 \\
74627463746474657466746774681 \\
746827468374684746857468674687 \\
7468974697470747107471174720\end{array}$ & & \\
\hline
\end{tabular}


TABLE E2. Continued

\begin{tabular}{|c|c|c|c|}
\hline Comorbidity & ICD-9 diagnosis codes & $\begin{array}{l}\text { ICD-9 procedure } \\
\text { code }\end{array}$ & CPT codes \\
\hline & $\begin{array}{l}74721747227472974737473174732 \\
74739747407474174742747497475 \\
74767476074761747627476374764 \\
74769747817478274783747897479\end{array}$ & & \\
\hline End-stage renal disease & $\begin{array}{l}403014031140391404024040140403 \\
\quad 4041240492404935856\end{array}$ & & \\
\hline Bleeding & $\begin{array}{l}9981143043143204321432942304233 \\
456045620459053021531053100 \\
5310153125312053121532053200 \\
5320153225322053221533053300 \\
5330153325332053321534053400 \\
534015342534205342156935785780 \\
5781578953145314053141531653160 \\
5316153245324053241532653260 \\
5326153305330053301533453340 \\
53340153365336053361534453440 \\
5344153465346053465350153511 \\
535215353153541535515356153571 \\
5997599705997171917191071911 \\
719127191371914719157191671917 \\
7191871919784878637863078639 \\
784736281362433636136362\end{array}$ & & \\
\hline
\end{tabular}

ICD-9, International Classification of Diseases ninth revision; $C P T$, Current Procedural Terminology.

TABLE E3. International Classification of Diseases ninth revision (ICD-9) and Current Procedural Terminology (CPT) codes for posttransplant complications

\begin{tabular}{|c|c|c|}
\hline Complication & ICD-9 diagnosis codes & CPT codes \\
\hline Stroke & $\begin{array}{l}3466034661346623466343043143204321432943301 \\
4331143321433314338143391434043400434014341 \\
43410434114349434904349143699702\end{array}$ & \\
\hline Acute renal failure & 58455846584758485849 & \\
\hline Pneumonia & $\begin{array}{c}003220203020402050212022103100391052105510730 \\
0830112411401144114511505115151159513041363 \\
4800480148024803480848094814820482148224823 \\
48230482314823248239482448240482414824248249 \\
48284828148282482834828448289482948348304831 \\
483848414843484548464847484848548651305171\end{array}$ & \\
\hline Sepsis & 9959199592 & \\
\hline Respiratory failure & $\begin{array}{l}5173518551851518525185351881518825188351884 \text { V461 } \\
\quad \text { V4611 V4612 V4613 V4614 V462 }\end{array}$ & \\
\hline Acute kidney injury & 5849 & \\
\hline Embolization & 44494442244421557036230444894332433859381 & \\
\hline Acute heart failure & 4282142823428314284042841428434280 & \\
\hline Re-exploration & & 35820 \\
\hline Intra-aortic balloon pump & & 33967 \\
\hline Extracorporeal membrane oxygenation & & 339603396136822 \\
\hline Tracheostomy & & 3160031601 \\
\hline
\end{tabular}

ICD-9, International Classification of Diseases ninth revision; $C P T$, Current Procedural Terminology. 
TABLE E4. Multivariable analysis for all-cause mortality at 3 years*

\section{Preoperative patient} characteristic
Hazard ratio $(95 \%$

confidence interval)

$P$ value

\begin{tabular}{|c|c|c|}
\hline \multicolumn{3}{|l|}{ Bridge to transplant } \\
\hline $31-365 d$ & $0.41(0.21-0.82)$ & .01 \\
\hline$>365 \mathrm{~d}$ & $0.39(0.19-0.80)$ & .01 \\
\hline No bridge to transplant & $0.46(0.23-0.91)$ & .03 \\
\hline Age $(y)$ & $1.00(0.99-1.01)$ & .84 \\
\hline Male & $1.04(0.82-1.32)$ & .74 \\
\hline Chronic kidney disease & $1.25(1.02-1.53)$ & .03 \\
\hline Hemodialysis & $1.06(0.75-1.50)$ & .74 \\
\hline Pneumonia & $1.64(1.34-2.01)$ & .00 \\
\hline Congestive heart failure & $0.49(0.23-1.05)$ & .07 \\
\hline Peripheral vascular disease & $1.00(0.82-1.23)$ & .98 \\
\hline Pulmonary circulatory disease & $0.98(0.80-1.19)$ & .82 \\
\hline Stroke & $1.08(0.84-1.39)$ & .54 \\
\hline $\begin{array}{l}\text { Chronic obstructive } \\
\text { pulmonary disease }\end{array}$ & $0.85(0.69-1.05)$ & .14 \\
\hline Diabetes & $1.15(0.94-1.40)$ & .18 \\
\hline Liver failure & $1.11(0.84-1.48)$ & .46 \\
\hline Coagulopathy & $1.00(0.80-1.24)$ & .97 \\
\hline Obesity & $1.31(0.97-1.76)$ & .08 \\
\hline Weight loss & $0.88(0.63-1.22)$ & .45 \\
\hline Anemia & $1.10(0.89-1.36)$ & .37 \\
\hline Hypertension & $1.17(0.91-1.50)$ & .22 \\
\hline \multicolumn{3}{|c|}{ LVAD complications within $30 \mathrm{~d}$ of heart transplant } \\
\hline Mechanical complications & $0.95(0.57-1.57)$ & .83 \\
\hline Pump thrombosis & $0.89(0.44-1.80)$ & .74 \\
\hline Local/systemic infection & $1.24(0.74-2.10)$ & .42 \\
\hline Any major bleeding event & $2.07(1.22-3.53)$ & .01 \\
\hline Any LVAD complication & $0.86(0.47-1.59)$ & .64 \\
\hline
\end{tabular}

Chronic kidney disease

dialys is

Congestive heart failure

Peripheral vascular disease

Pulmonary circulatory disease

Stroke

Diabetes
No bridge to transplant

$0.41(0.21-0.82)$

$1.00(0.99-1.01)$

$L V A D$, Left ventricular assist device. *Reference of hazard ratio for bridge to transplant is bridge to transplant duration $<31 \mathrm{~d}$. 